\section{Morfologia Avaliativa: o estatuto independente de -inh e -zinh no Português Brasileiro, composição e pejoratividade}

Evaluative Morphology: the independent status of -inhe -zinh in Brazilian Portuguese, composition and pejorativity

Marcela Nunes COSTA (UNIFESP) marcela.backy@gmail.com

Rafael Dias MINUSSI (UNIFESP) rafaelminussi@yahoo.com.br

Recebido em: 30 de jan. de 2019. Aceito em: 22 de maio de 2019.
COSTA, Marcela Nunes, MINUSSI,

Rafael Dias. Morfologia Avaliativa: o

estatuto independente de -inh e -zinh no Português Brasileiro, composição

e pejoratividade. Entrepalavras,

Fortaleza, v. 9, n. 2, p. 154-172, maioago/2019.

Resumo: Este trabalho visa à investigação da morfologia avaliativa no Português Brasileiro (PB) por meio da análise de dados com os sufixos de diminutivo -inh e -zinh. Busca-se responder a questões sobre o estatuto desses sufixos tomando como base trabalhos que já se debruçaram sobre o assunto, como o de Bisol (2010). Temse como objetivos (i) investigar a possível independência de -zinh através de dados que se realizam apenas com esse sufixo, como os pronomes, alguns prefixos e artigos no $\mathrm{PB}$ e (ii) examinar a possibilidade da leitura pejorativa das formações diminutivas. Serão observados dados de corpora do PB com esses sufixos com base nos pressupostos teóricos da Morfologia Distribuída, uma teoria nãolexicalista que propõe que tanto palavras quanto sentenças são formadas no mesmo componente gerativo, a Sintaxe. Assim, este artigo dialoga com autores como Marantz (2001), Arad (2003), Bachrach e Wagner (2007) e Armelin (2015), que explicam e utilizam o modelo teórico da Morfologia Distribuída ou promovem análises nãolexicalistas. Como resultado, defendemos que -zinh é independente de -inh e que esses formadores se diferenciam na estrutura sintática pois -zinh tem a natureza de uma raiz, além de associarmos a pejoratividade à composicionalidade das formações.

Palavras-chave: Morfologia Avaliativa. Composição. Pejoratividade. 


\begin{abstract}
This paper aims to investigate the evaluative morphology in Brazilian Portuguese (PB) by means of data analysis with the suffixes of diminutive -inh and -zinh. It seeks to answer questions about the status of these suffixes based on works that have already addressed the issue, such as Bisol (2010). We intend to (i) investigate the possible independence of -zinh through data that are only performed with this suffix, such as pronouns, some prefixes and articles in $\mathrm{PB}$, and (ii) explore the possibility of pejorative reading of the diminutive formations. $\mathrm{PB}$ corpora data with these suffixes will be observed based on the theoretical assumptions of Distributed Morphology, a non-lexical theory that proposes that both words and sentences are formed in the same generative component, Syntax. Thus, this article dialogues with authors such as Marantz (2001), Arad (2003), Bachrach and Wagner (2007) and Armelin (2015), who explain and use the theoretical model of Distributed Morphology or promote nonlexical analysis. As a result, we argue that -zinh is independent of -inh and that these elements differ in the syntactic structure because -zinh is a root; besides, we associate the pejorative evaluation with the compositionality of the formations.
\end{abstract}

Keywords: Evaluative Morphology. Composition. Pejorativity.

\title{
Introdução
}

Este artigo apresenta uma análise para os diminutivos do Português Brasileiro (PB), nomeadamente -inh e -zinh, que pretende observar, por meio da Morfologia Distribuída (cf. MARANTZ, 2001; $A R A D, 2003)$, uma teoria não-lexicalista que prevê a formação tanto de sentenças quanto de palavras através de processos sintáticos, o comportamento presumidamente diferenciado que esses elementos apresentam entre si. Propõe-se que as diferenças na atuação destes elementos no PB são explicadas pela natureza diversa desses elementos.

Como consequência dessa natureza diversa, os elementos ocupam diferentes posições na estrutura sintática e, a partir desse comportamento, observado nos dados, defendemos que esses elementos são formas independentes na gramática e atuam de modo independente no processo de formação de palavras, contrariando hipóteses que afirmam que -inh e -zinh são o mesmo elemento e se diferenciam por razões fonológicas e pela posição que ocupam na computação sintática (cf. BISOL, 2010; LEE, 1999; BACHRACH; WAGNER, 2007). Argumentamos que -zinh é uma raiz, enquanto -inh é a realização de um traço de diminutivo na estrutura sintática. Assim sendo, busca-se explorar dados que apontam para uma categorização ainda mais específica sobre as diferenças entre esses elementos, nomeadamente a possibilidade de tratar as formações em -zinh como participantes de um processo de composição. Para tanto, será utilizado o Corpus do Português, desenvolvido pela Brigham Young University, uma plataforma online e gratuita para o acesso a dados de corpora. 
V. 9 (2)

$154-172$

maio-ago 2019
Ainda, com base no fenômeno da (não) composicionalidade dos formadores de diminutivo, pretende-se propor uma análise sintática que explique e permita prever alterações semânticas e idiomáticas nas formações diminutivas, por exemplo, quando há interpretação avaliativa derivada do uso de -inh. Assim, a literatura que serve de base para a discussão dos fenômenos descritos é desenvolvida a seguir.

A morfologia de diminutivos do $\mathrm{PB}$ vem sendo amplamente discutida por meio dos diversos vieses de análise de formação de palavras. Uma dessas discussões é a desenvolvida por Bisol (2010) por meio da Teoria da Otimidade. A autora faz um apanhado dos estudos que já se debruçaram sobre os diminutivos do $\mathrm{PB}$, como as gramáticas da língua portuguesa de Barbosa (1875) e de Maciel (1925), assim como estudos mais recentes, nomeadamente Leite (1974), Câmara Jr. (1975), Menuzzi (1993) e Ferreira (2005).

Em suma, a autora defende que o único elemento participante na formação de palavras é -inh, de forma que a consoante /z/ seria requerida apenas para satisfazer necessidades fonológicas como:

(1) a. Evitar um hiato: mãe $>$ *mãeinha > mãezinha

b. Ser fiel a traços fonológicos da base: café > cafeinho* $>$ cafèzínho

c. Preservar bordas: amor $>$ *amorinho $>$ amorzinho

d. Preservar um acento marcado: aldeão $>$ *aldeãoinho $>$ aldeãozinho

e. Ter correspondência com formas de output: cores $>*$ coreinhas $>$ corezinhas

Apesar disso, podemos encontrar diferenças entre -inh e -zinh no que diz respeito à composicionalidade, pois dados demonstram que -inh apresenta tanto a leitura composicional quanto a nãocomposicional, enquanto -zinh permite apenas a leitura composicional, todas aceitas pela língua e utilizadas pelos falantes. Vejamos como isso se dá.

(2) a. Amarel-inh-a

Interpretação composicional: Cor amarela clara.

Interpretação não-composicional: Jogo infantil em que as crianças pulam sobre números riscados no chão; 
b. Amarela-zinh-a

Interpretação composicional: Cor amarela clara.

Interpretação não-composicional: $\varnothing$

(3) a. Escol-inha

Interpretação composicional: Escola pequena.

Interpretação não-composicional: Escola de educação infantil;

b. Escola-zinha

Interpretação composicional: Escola pequena. Interpretação não-composicional: $\varnothing$

Levando isso em consideração, por meio de uma análise sintática da formação de palavras, Armelin (2015) defende que tanto -inh quanto -zinh têm caráter subjacente na língua, mas que a consoante /z/ tem estatuto duplo, pois pode participar tanto de necessidades fonológicas da formação de palavras quanto como parte do formador -zinh. A autora discute, ainda, o proposto por Bachrach e Wagner (2007) sobre a comparação entre os diminutivos aqui estudados e os compostos coordenados no $\mathrm{PB}$, como porco-zebra, que definem os valores gramaticais a partir do primeiro item do composto, considerado o núcleo. Segundo os autores, tanto os compostos coordenados quanto os diminutivos seriam resultado de um processo de adjunção sintática.

Este artigo, como anteriormente dito, pretende (i) debater as ideias de Bachrach e Wagner (2007), uma vez que, ao argumentarmos a favor do status de raiz para zinho, este elemento pode participar da formação de compostos; além de (ii) discutir propostas de outros autores de forma a advogar em favor da independência dos formadores de diminutivo e (iii) propor um novo olhar sobre as discussões feitas até o momento por meio da Morfologia Distribuída (doravante MD), principalmente, mediante a teoria de fase nas palavras de Marantz (2001) e Arad (2003), desenvolvidas a seguir.

Marantz (2001) assume que os dois lugares para a formação de palavras (flexão e derivação) se diferenciam pela posição que os elementos ocupam na estrutura sintática, de forma que utiliza a noção de fase de Chomsky (2001) para estabelecer quais são esses lugares. O primeiro seria o domínio das raízes: anexando um morfema à raiz ainda sem categorização sintática (nome, verbo ou adjetivo), estaríamos criando uma fase ao determinar a categoria da raiz; o segundo seria 
V. 9 (2)

$154-172$

maio-ago

2019

fora do domínio do categorizador funcional que determina a categoria sintática, os v's, n's e a's. Segundo essa proposta, quando um categorizador se concatena a uma raiz já categorizada, ele tem acesso apenas às características locais dessa fase, não à identidade da raiz, que na primeira categorização cria uma interpretação idiossincrática. Ou seja, uma vez categorizada, suas informações são encaminhadas para PF (Phonological Form) e LF (Logical Form), o que resulta na negociação de significado da raiz e essa passa a ter uma interpretação que é levada até o final da derivação. Assim, a seleção de requisitos para a formação de morfemas ocorre localmente à informação já categorizada.

Arad (2003), baseando-se na proposta de Marantz (2001), assume as raízes como elementos desprovidos de material funcional e considera a formação de palavras a partir de raízes como idiossincrática, e por isso permite a leitura não-composicional, assim como a formação de palavras a partir de palavras como composicional, pois, uma vez que o significado é fixado junto à concatenação do primeiro núcleo categorizador, a interpretação deverá se manter estável durante toda a derivação, conforme já dissemos antes. Essa proposição é chamada de restrição de localidade (locality constraint) e é universal, ou seja, deve ser encontrada em todas as línguas naturais.

Assim, os temas estão divididos como segue: inicia-se com a análise mais atenta sobre as semelhanças entre os formadores de diminutivo e os compostos coordenados; apresentam-se, então, dados que podem indicar a independência dos formadores por meio da análise de -zinh como uma raiz; discute-se a leitura avaliativa dos formadores por meio da análise da pejoratividade; conclui-se com um breve resumo da discussão e sistematização dos dados.

\section{Análise de diminutivos como compostos}

Serão discutidas nas subseções seguintes as semelhanças apresentadas entre os diminutivos e os compostos, como propõem Bachrach e Wagner (2007). No entanto, ao final da discussão, ao contrário do que concluem os autores sobre os diminutivos, buscaremos mostrar de forma clara, e dialogando com a análise de Armelin (2015), a natureza morfológica de raiz para zinho e a independência entre zinho e -inho. Desse modo, se considerarmos zinho como derivado da raiz $\sqrt{ }$ ZINH, poderemos expor a relação entre os diminutivos e os compostos, pois os compostos são formados por duas bases ou raízes. Após essa 
discussão, dados relevantes para esta análise serão observados quanto à composicionalidade das formações diminutivas e as implicações sintáticas presentes na leitura idiomática avaliativa.

\section{Proposta de Bachrach e Wagner (2007)}

Os autores defendem que o primeiro item de um composto coordenado é o núcleo, pois é a partir dele que serão definidos os valores como o gênero do composto e a concordância número-pessoal. Assim, em compostos como os apresentados nos exemplos em (4) abaixo, reproduzidos de Bachrach e Wagner (2007, p. 2), alterando-se a ordem dos itens obtêm-se valores diferentes de gênero:
(4) a. Um porco-zebra belo (masc.)
b. Uma zebra-porco bela (fem.)

Ainda, os autores assumem que o segundo item do composto coordenado funciona como um adjunto da formação porque recebe marca de número separadamente do primeiro item, de forma que a adjunção se realizaria no nó de número da estrutura sintática, como pode ser visto em (5) para o composto coordenado porco-zebra.

(5) Estrutura sintática dos compostos coordenados

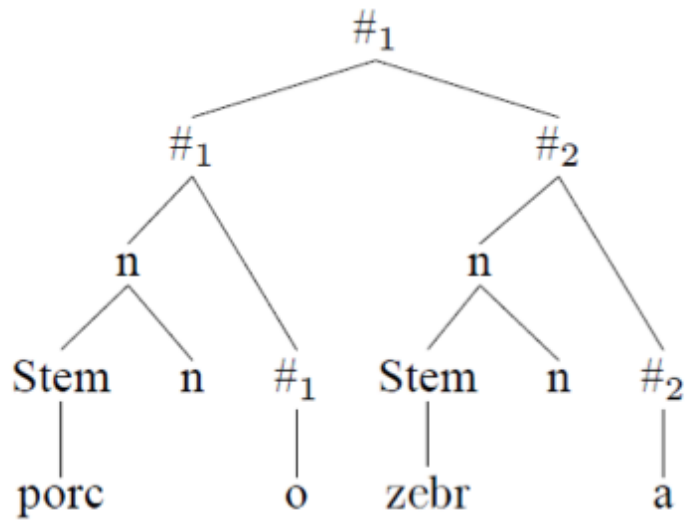

(BACHRACH; WAGNER, 2007, p. 3)

No entanto, Armelin (2015) contrapõe a possibilidade de gênero e número estarem agrupados na mesma projeção com base em Fuchs, Polinsky e Scontras (2014), que desenvolvem um estudo utilizando small clauses do espanhol que demonstra que, se gênero e número estivessem agrupados na mesma projeção, os valores de agramaticalidade de 
v. 9 (2)

154-172

maio-ago 2019

concordância de gênero e número seriam interpretados da mesma forma pelos falantes, mas esse não é o caso. Assim, em paralelo com Armelin (2015), o presente artigo assume que gênero e número formam projeções diferentes na computação sintática.

Com relação à exemplificação de Bachrach e Wagner (2007) para a formação de compostos coordenados, porco-zebra não é o melhor dado, visto que "zebra" é um nome comum para feminino e masculino, uma vez que não há zebro'. Além disso, ambos os nomes são animados e possuem gênero sexual, o que pode enviesar a análise.

Ademais, para Bachrach e Wagner (2007), os diminutivos assumem a mesma configuração dos compostos coordenados uma vez que são formados a partir de um núcleo e do formador de diminutivo, que recebe as informações de gênero e número-pessoal a partir do núcleo. Dessa forma, os autores propõem que existam duas alturas possíveis para a concatenação dos diminutivos na estrutura sintática: abaixo ou acima do nó de número.

O diminutivo baixo, de acordo com a nomenclatura dos autores, representa a forma não encabeçada por consoante, ou seja, -inh, e seria concatenado como um adjunto do núcleo, recebendo posteriormente a marca de gênero e número, como pode ser visto em (6) para a formação de amiguinho.

(6) Estrutura sintática da adjunção do diminutivo baixo

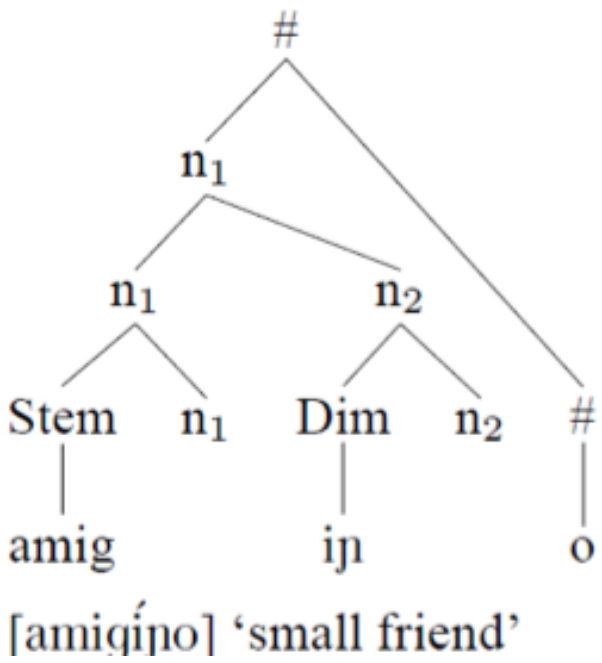

(BACHRACH; WAGNER, 2007, p. 5)

Por outro lado, a adjunção do diminutivo alto se daria a partir do nó de número, de forma que, assim como ocorre com os compostos coordenados, os valores gramaticais seriam recebidos separadamente, como demonstra a estrutura sintática da formação da palavra amigozinho em (7).

\footnotetext{
${ }^{1}$ Consideramos que zebro não existe na língua, apesar de ser uma palavra possível.
} 
(7) Estrutura sintática da adjunção do diminutivo alto

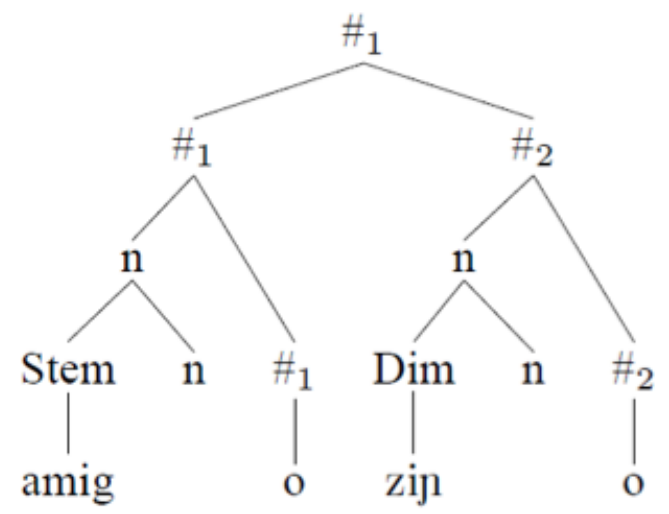

[amigozíno] 'small friend'

(BACHRACH e WAGNER, 2007, p. 5)

No entanto, Armelin (2015, p. 135) discorda da hipótese de que os formadores de diminutivo teriam estruturas semelhantes às de compostos coordenados, pois enquanto os últimos permitem que haja formações em que o primeiro item do composto não concorda em gênero com o segundo, no caso dos diminutivos, isso não é possível, já que eles concordam obrigatoriamente com o gênero da raiz. Se a semelhança fosse confirmada, a autora argumenta que formações como *professorazinho ou *porcazinho seriam possíveis na língua.

Refletindo sobre o argumento de Armelin(2015), podemos observar, no entanto, que também em compostos coordenados como ator-diretor, cantora-atriz, quando não há concordância de gênero entre os itens do composto, há formações agramaticais, por exemplo, *atordiretora, *cantor-atriz, de modo que a afirmação de Armelin (2005), contra o tratamento dos formadores de diminutivo como compostos, é enfraquecida. Não parece que a concordância de gênero entre os membros do composto seja um parâmetro para dizer que a estrutura dos diminutivos não possa ser como a de um composto coordenado.

Ainda, Bachrah e Wagner (2007) tratam das diferenças de escopo dos formadores de diminutivo observando as formações do tipo adjetivo-nome em que há leitura idiomática. Para os autores, quando -inh se concatena à formação, a leitura idiomática é perdida, enquanto com a concatenação de -zinh isso não ocorre. Isso é explicado pelo fato de -inh ser o formador baixo, de forma que sua concatenação interferiria no domínio da primeira fase (cf. CHOMSKY, 2001; MARANTZ, 2001; ARAD, 2003). Os exemplos utilizados pelos autores para ilustrar a situação são os que seguem².

\footnotetext{
${ }^{2}$ Consideramos que zebro não existe na língua, apesar de ser uma palavra possível.
} 
v. 9 (2)

$154-172$

maio-ago

2019
(8) a. super amigo

b. ??super amiguinho

c. super amigo zinho super herói)

(9) a. bom conselho

b. ??bom conselhinho

c. bom conselho zinho 'super hero' (super herói)

??

'small super hero' (pequeno

'good advice'

??

'small piece of good advice'

A princípio, deve ser ressaltada a interpretação que é dada aos dados em (8) uma vez que, para (a) "super amigo", não necessariamente tem-se a interpretação de "super herói" no PB, como sugerem os autores, assim como em (b) a interpretação de "super amiguinho" é facilmente derivada composicionalmente como "super amigo pequeno", enquanto em (c) "super amigozinho" não parece ser a escolha mais frequente pelos falantes de PB, mesmo que a interpretação composicional continue cristalina como em (b). Ainda, em relação à leitura idiomática, dificilmente os dados em (8) poderiam receber outro sentido além do composicional no $\mathrm{PB}$, mas mesmo que recebessem, os autores não o explicam. A mesma argumentação pode ser utilizada para os dados em (9), já que em (a) não parece existir leitura idiomática, em (b) o significado composicional é cristalino e em (c) a frequência de uso pode ser questionada.

Armelin (2015) argumenta sobre as formações do tipo adjetivonome, como as apresentadas em (8) e (9), no mesmo sentido defendido aqui, ou seja, a leitura composicional é preservada com a anexação de -inh e preferida em comparação à anexação de -zinh. No entanto, os dados apresentados pela autora, reproduzidos em (10), apesar de apresentarem leitura idiomática, pouco contribuem para essa discussão, pois não é comum o falante do PB utilizar os formadores de diminutivo nas formações do tipo adjetivo-nome ${ }^{3}$.

(10) Anexação do diminutivo em sequências adj-nome não composicionais
a. boa vida
boa vidinha/?boa-vidazinha
b. boa praça
boa pracinha/?boa praçazinha
c. bons olhos
bons olhinhos/ ?bons olhozinhos

3 Mantivemos a tradução para o inglês, porque ela sugere a interpretação dada aos dados pelos autores. Tal fato pode contribuir para entendermos a análise realizada. 
Apesar de observarem que há diferenças morfológicas, sintáticas e semânticas entre as formas de diminutivo, Bachrach e Wagner (2007) não consideram -zinh e -inh como formadores independentes. A escolha é motivada, então, pelo ambiente fonológico em que se encontram, como para evitar um hiato, de forma que, para os autores, a consoante /z/ é epentética. Dessa forma, o diminutivo baixo também pode ser pronunciado como -zinh.

Para demonstrar essa proposta, os autores apresentam a classe de nomes que não possuem vogal temática, ou seja, possuem um $\varnothing$ morfológico, sendo terminados por uma consoante. Assim, nessas formações, como exemplifica (11), o diminutivo é concatenado fora de $n$ se tomarmos a estrutura em (7) e o diminutivo com [z] inicial é desencadeado. Apesar disso, um dos exemplos utilizados para demonstrar que o mesmo ocorre com outros sufixos apresenta dados que podem ou não funcionar no $\mathrm{PB}$, como segue:

(11) flor florzinho floreiro 'gardener'
(BACHRACH; WAGNER, 2007, p. 9)

No $\mathrm{PB}$, flor é uma palavra feminina, de modo que a forma "florzinho", apesar de possível, não se instancia. Semelhantemente, a sufixação em -eir é comumente seguida da vogal -a, default para feminino na língua, e poderia levar a outra interpretação que não 'gardener' (jardineiro), mas "recipiente onde se planta as flores". Apesar disso, é possível encontrar tanto a forma "floreiro" quanto "floreira", ambas podendo significar a pessoa que vende flores, não necessariamente quem cuida do jardim (jardineiro), ou o recipiente em que se planta as flores. Assim, o conjunto de dados para a derivação do nome flor pode ser expresso como segue:
(12) flor
florzinha
floreira
/floreiro

Ainda, os autores postulam que a ambiguidade entre os sufixos pode ser desfeita no plural, como segue:

(13) Singular
a. flor
b. $\left.\left[\left[[\text { flor }]_{n}[\text { zinh }]_{n}\right]_{n}\right] a\right]_{\text {num }}$
c. $\left[[\text { flor }]_{\text {num }}[\text { zinha }]_{\text {num }}\right]_{\text {num }}$ 
V. 9 (2)

$154-172$ maio-ago 2019
Plural
a. flores
b. $\left[[\text { flor }]_{n}[\text { zinh }]_{n}\right]$ a s $]_{\text {num }}$
c. [[flores $\left.\left.]_{\text {num }}\right][\text { inhas }]_{\text {num }}\right]_{\text {num }}$
(BACHRACH; WAGNER, 2007, p. 9)

Assim como a escolha de florzinhas ou florezinhas implica em interpretações diferentes:

(14) 'Look at the flowers (dim)!' (Olhe para as flores (dim)!)

a. florzinhas: 'flores que são pequenas'

b. florezinhas: 'pequenas flores'

(adaptado de BACHRACH e WAGNER, 2007, p. 9)

Apesar disso, os dados em (13) e (14) podem ser questionados, pois a diferenciação de significado entre as formas em -inh e -zinh apresentada não parece ser usual no PB, de forma que ambos levariam à interpretação composicional de "flores pequenas".

\section{Análise de dados}

Considerando o que foi discutido até o momento, partimos agora para a análise dos dados do PB que apresentam algumas particularidades. Inicialmente, discutiremos o estatuto dos formadores de diminutivo quanto à dependência, retomando a hipótese de Bachrach e Wagner (2007) e Bisol (2010) de que -zinh seria fruto de um processo de epêntese para evitar um hiato, ou independência, como pretendemos defender.

A princípio, Bachrach e Wagner (2007) defendem que tanto o diminutivo alto quanto o diminutivo baixo podem ser realizados como -zinh por questões fonológicas, de forma que a ambiguidade do uso do formador poderia ser resolvida quando observado o plural da palavra. Essa hipótese, porém, deixa de analisar dados em que zinho é um nome. Os autores citam essa possibilidade em uma nota de rodapé (BACHRACH; WAGNER, 2007, p. 5), mas não a discutem. Segundo eles, o nome zinho independente se aproxima ainda mais dos compostos, o que também defendemos neste trabalho. Observemos o dado com zinha (fem.) retirado do Corpus do Português ${ }^{4}$.

4 Foram encontradas 183 ocorrências de zinha no Corpus do Português. Dados com zinho (masc.) não foram encontrados fora da condição de apelido. 
(15) Um relacionamento de 4 anos acabar por causa de uma zinha que se diz ser cigana. (grifo meu)

(Fonte:<http://magiadobem.blogspot.com.br/2013/01/ simpatia-para-separar-casal.html)

O dado com zinha interessa para a análise que propomos, pois pode indicar a possibilidade de uma raiz que recebe um categorizador $n$ e a marcação de gênero feminino, por meio da vogal $a^{5}$. Ainda considerando as estruturas de Bachrach e Wagner (2007), pode-se observar que considerar zinh- como uma raiz não prejudica em nada a noção de fase apresentada em Marantz (2001), de forma que a estrutura que comporta zinh- enquanto raiz, baseada em Bachrach e Wagner (2007), pode ter a configuração apresentada em (16).

(16) Estrutura para zinha

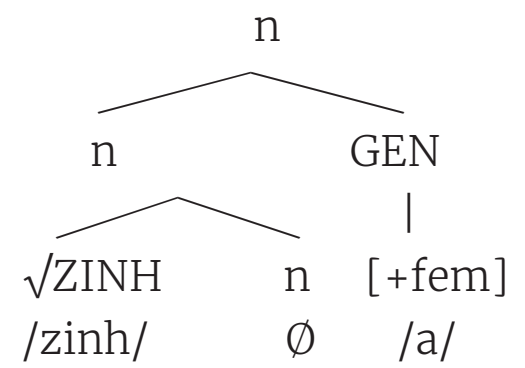

Uma possibilidade que se abre a partir do exemplo em (16) é a do uso de "umazinha", como no exemplo (17), em que há a junção do artigo indefinido ao formador de diminutivo, reconhecido agora como uma raiz e empregado no exemplo abaixo:

(17) a. Fulano deu umazinha.

b. *Fulano deu uminha.

A partir do exemplo em (17), a argumentação desenvolvida para zinha não é prejudicada, pois uma não parece ser formado por uma raiz, mas por meio de um núcleo funcional, de modo que a formação de umazinha se daria a partir da raiz $\sqrt{ }$ zinh. A leitura composicional, no entanto, não é dada em umazinha, mas pela expressão "dar umazinha". Por sua vez, o exemplo em (17)b nos parece agramatical, o que fortalece

\footnotetext{
${ }^{5}$ Não está no escopo desse artigo uma discussão sobre a natureza desta vogal, se é a realização de um categorizador, se é uma vogal temática, ou a marca de gênero feminino. Para uma discussão sobre vogal temática, ou de classe e gênero nos diminutivos, ver Armelin (2015).
} 
V. 9 (2)

$154-172$ maio-ago 2019 o argumento de que zinh- é uma raiz e o núcleo funcional um precisa estar concatenado a uma raiz, não podendo estar concatenado apenas a outro núcleo funcional, no caso +DIM, realizado como -inh.

Partindo desses dados, temos evidências de que os falantes atribuem ao formador de diminutivo -zinh diferenças em relação a -inh tanto semânticas quanto morfológicas. Outro dado em favor da análise de zINH como raiz é a possibilidade de anexação de diminutivo a um pronome, como observado nos dados a seguir. Nossa hipótese é a de que os pronomes são realização de traços (pessoa, número e gênero; traços phi), ou seja, são funcionais sem material lexical (raiz), de modo que podem estar afixados a uma raiz, que nos exemplos abaixo é realizada por zinh-.

(18) Dados do Corpus do Português

a. Nada de bom a oferecer, fica na tuazinha! (grifo meu) (Fonte:<http://www.pimentanoteuerefresco.com. br/2013/08/mais-gentileza-por-favor.html>)

b. Imagina, euzinha por exemplo, sei danças árabes sagradas. (grifo meu) (Fonte:<http://atitudesustentavel.com.br/ istoegaia/2012/05/01/a-vaquinha-que-nao-foi-probrejo-2-dicas-para-ser-feliz-com-menos-dinheiro/>)

c. Euzinho aqui sou só o mensageiro. (grifo meu) (Fonte:<https://informaticaemportugues.wordpress. com/2012/11/>)

A argumentação desenvolvida para as formações com o artigo indefinido é válida, então, para a representação sintática dos dados com pronomes, já que ambos não são considerados raízes, como é visto na estrutura abaixo:

(19) Output: tuazinha

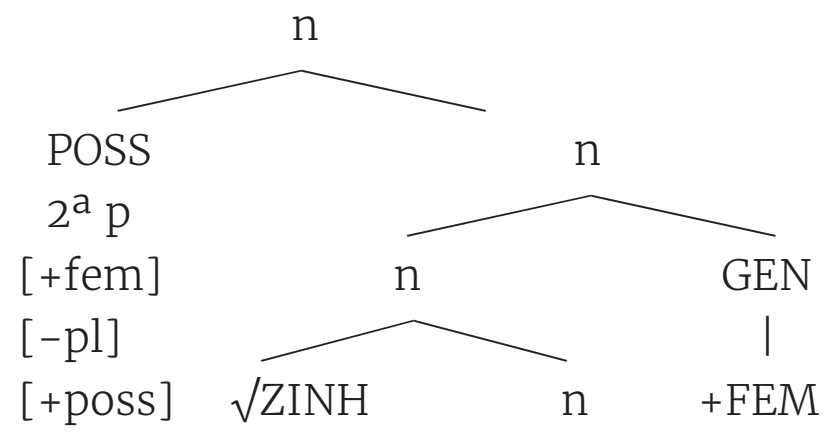


Outro tipo de dado que nos leva em direção à análise de -zinh como raiz é a possibilidade de concatenação a prefixos. Schwindt (2001) divide os prefixos entre composicionais e legítimos, sendo os primeiros vocábulos fonológicos independentes, compostos autênticos que podem receber acento e se estabelecer como formas livres, enquanto os últimos são sílabas átonas adjuntas ou incorporadas à base a que se ligam, além de possuírem características de clíticos e não poderem receber acento. A análise aqui proposta leva em consideração os prefixos do primeiro grupo, ou seja, os chamados composicionais para Schwindt (2001), pois os prefixos legítimos, como clíticos, não se estabelecem como vocábulos fonológicos independentes.

A lista em (20) é uma relação de alguns dos prefixos composicionais relevantes para esta análise, utilizados por Schwindt (2001), e suas contrapartes em -zinh e -inh.

$\begin{array}{lll}\text { (20) Prefixo } & \text {-zinh } & \text {-inh } \\ \text { a. extra } & \text { extrazinho } & \text { *extr-inha } \\ \text { b. hiper } & \text { hiperzinho } & * \text { hiper-inho } \\ \text { c. infra } & \text { infrazinho } & * \text { infr-inha } \\ \text { d. macro } & \text { ?macrozinho } & * \text { macri-nho } \\ \text { e. micro } & \text { microzinho } & * \text { micr-inho } \\ \text { f. mono } & \text { monozinho } & * \text { mon-inho } \\ \text { g. neo } & \text { neozinho } & * \text { neo-inho } \\ \text { h. es } & \text { exzinho } & * \text { ex-inho } \\ \text { i. pós } & \text { poszinha } & * \text { pos-inha } \\ \text { j. pré } & \text { prezinho } & * \text { pre-inho }\end{array}$

Pode-se observar nos dados em (20) que há preferência por -zinh nas formações que envolvem os prefixos, de forma que, retomando a discussão da possibilidade de zinha como forma independente e consequentemente a defesa de -zinh enquanto raiz, é possível estabelecer que, não tendo estatuto de raiz, os prefixos recebem acento secundário, enquanto zinha carrega o acento como todas as raízes.

\section{A composicionalidade nos diminutivos}

Os formadores de diminutivo do PB fazem parte da chamada morfologia avaliativa, de modo que o uso desses formadores pode ter características composicionais e não-composicionais, como 
V. 9 (2)

$154-172$

maio-ago 2019 discutido anteriormente. A leitura não-composicional, não raro, pode ser acompanhada de um tipo de avaliação que pode ser classificada de modo geral entre afetividade, pejoratividade e intensificação (cf. TAVARES,1999).

Propomos a análise da leitura não-composicional em função da estrutura, tomando o fenômeno da pejoratividade para exemplificar a avaliação nos formadores de diminutivo. Para tanto, foram observados dados que não apresentam base já marcadamente pejorativa, como é o caso do nome cadela, que pode ser interpretado pelos falantes tanto como "fêmea de cachorro" quanto como "sinônimo de vagabunda". Os dados, então, serão examinados quanto à anexação de -inh e -zinh a bases não pejorativas e as leituras resultantes da formação.

Retomando a discussão de Marantz (2001) e Arad (2003) já iniciada na introdução deste trabalho, o diminutivo considerado baixo por Bachrach e Wagner (2007) se anexa diretamente à raiz não categorizada, formando uma palavra a partir da raiz (primeira fase), enquanto o diminutivo alto se anexa a uma raiz já categorizada (fase externa, quando já houve a negociação de significado), formando uma palavra a partir de uma palavra.

O diminutivo formado a partir da primeira fase, então, apresenta maior não-composicionalidade pelo fato de não ter material de qualquer espécie interferindo entre a raiz e o formador de diminutivo, enquanto o diminutivo formado depois da primeira fase é mais composicional porque o significado já foi negociado e há material interferindo entre a raiz e o formador de diminutivo. A estrutura sintática para os dados de amarelinha ((i) brincadeira e (ii) cor) e amarelazinha (representando apenas a cor), com base na proposta de Marantz (2001) e Arad (2003) e concordando com a proposta de Bachrach e Wagner (2007) de que o diminutivo alto é resultado de um processo de adjunção, como nos compostos coordenados, pode ser representada como em (21). 
(21) Estrutura sintática dos formadores de diminutivo a. Amarelinh(a) (brincadeira)

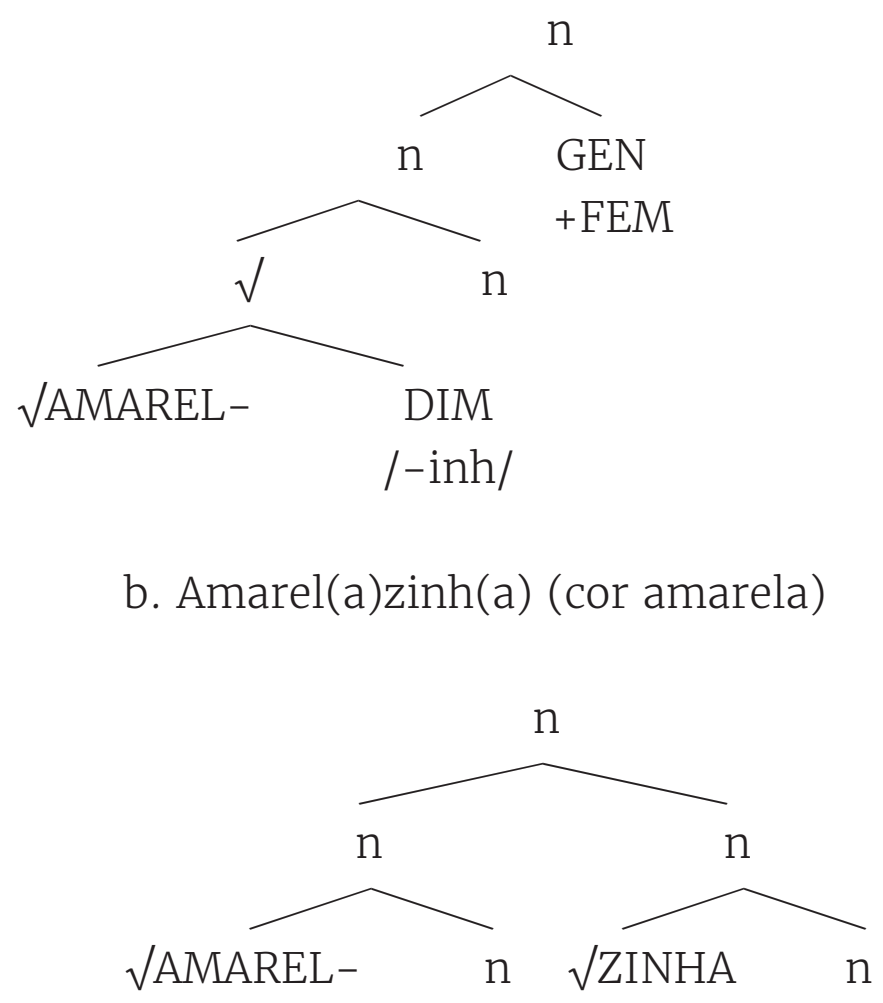

No exemplo em (21)a, temos a leitura não-composicional, pois o diminutivo está ligado diretamente à raiz e, posteriormente, tudo será categorizado pelo núcleo nominal. Já em (21)b, cada raiz é categorizada e tem seu significado negociado. Assim, segundo a teoria de fase descrita neste artigo, não é possível haver uma leitura nãocomposicional, de modo que a única interpretação é de cor amarela.

A leitura pejorativa, dessa forma, seria acessada, preferencialmente, por meio do uso de -inh, já que a primeira fase está atrelada à idiossincrasia da formação diminutiva. Os exemplos a seguir demonstram que as formações com -zinh não têm a preferência no acesso à leitura pejorativa:

(22) a. Que bonequinha cara.

b. *Que bonecazinha cara.

(23) a. Nunca entraria naquele carrinho.

b. *Nunca entraria naquele carrinhozinho.

(24) a. Era um modelinho bem fraco.

b. *Era um modelozinho bem fraco. 
v. 9 (2)

154-172

maio-ago

2019

(25) a. A casa não tem nem uma pinturinha?

b. *A casa não tem nem uma pinturazinha?

(26) a. Foi um banquetinho longe de especial.

b. *Foi um banquetezinho longe de especial.

Dessa forma, retomando toda a argumentação desenvolvida ao longo deste trabalho, com a observação dos dados pela leitura da pejoratividade, temos mais uma evidência em favor da independência dos formadores de diminutivo, pois há diferenças na estrutura sintática das formações com -inh e -zinh que também levam a diferenças semânticas por meio da composicionalidade.

\section{Conclusão}

Em suma, este trabalho defende a independência dos formadores de diminutivo -inh e -zinh por meio da análise de Bachrach e Wagner (2007) e Armelin (2015) sobre a possibilidade de -zinh participar de um processo de composição, enquanto -inh é realizado como um traço de diminutivo. A partir disso, procuramos defender que -zinh tem características que o aproximam do estatuto de raiz, como foi demonstrado a partir do exemplo com zinha, que pode ser realizado de forma independente, assim como a realização de umazinha, em que a formação se dá por meio da concatenação de um núcleo funcional, o artigo indefinido uma, à raiz -zinha.

Ainda, nas formações com pronomes, que são realizações de traços de pessoa, número e gênero, de forma que não apresentam material lexical, observa-se que as formações com -inh são agramaticais, enquanto as com -zinh são preferidas. Além disso, seguindo a análise de Schwindt (2001) para os prefixos, verifica-se que os composicionais apresentam preferência por -zinh tanto por questões fonológicas do acento quanto pela impossibilidade dos prefixos serem caracterizados como raízes, de forma que -zinh teria esse papel.

Por fim, buscamos apresentar, por meio da teoria de fase de Marantz (2001) e Arad (2003), que a avaliação nas formações diminutivas, neste caso particular a pejoratividade, está diretamente relacionada à composicionalidade dos formadores, pois assumimos que as formações consideradas gramaticais, e assim de uso mais frequente pelos falantes, são as com o formador que se anexa dentro da primeira fase, -inh. 


\section{Referências}

ARAD, M. Locality Constraints on the Interpretation of Roots: the Case of Hebrew Denominal Verbs. Natural Language and Linguistics Theory, v. 21, p. 737-778, 2003.

ARMELIN, P. R. G. A Relação entre Gênero e Morfologia Avaliativa nos Nominais do Português Brasileiro: Uma abordagem sintática da formação de palavras. 2015. 247f. Tese (Doutorado) Faculdade de Filosofia, Letras e Ciências Humanas, Universidade de São Paulo, São Paulo, 2015.

BACHRACH, A; WAGNER, M. Syntactically Driven Cyclicity vs. OutputOutput Correspondence: The Case of Adjunction in Diminutive Morphology. U. Penn Working Papers in Linguistics, Volume 10.1, 2007.

BARBOSA, J. S. Gramática Philosophica da Língua Portugueza. 6 ed. Lisboa: Typographia da Academia geral de Ciências de Lisboa, 1875 [1787].

BISOL, L. 0 Diminutivo e suas Demandas. DELTA, São Paulo, v. 26, n.1, p. 59-85, 2010. Disponível em: http://www.scielo.br/scielo.php?script=sci arttext\&pid=S0102-44502010000100003. Acesso em: 29 jan. 2019.

CÂMARA, J. M. J. História e Estrutura da Língua Portuguesa. Rio de Janeiro: Padrão, 1975.

CHOMSKY, N. Derivation by Phase. In: KENSTOWICZ, M. (ed.) Ken Hale: A life in language. Cambridge, MA: MIT, p. 1-52, 2001.

DAVIES, Mark. Corpus do Português. Brigham Young University, 2015. Disponivel em: https://www.corpusdoportugues.org/. Acesso em: 29 jan. 2019.

FERREIRA, M. Diminutives in brazilian portuguese and output-output correspondence. In: GESS, R; RUBIN, E. J. (editors). Theoretical and experimental approaches to romance linguistics. Salt Lake City, p. $109-123,2005$.

FUCHS, Z; POLINSKY, M; SCONTRAS, G. The Differential Representation of Number and Gender in Spanish. Paper presented at the 37th GLOW. Brussels, 2014 .

LEE, S. H. Sobre a formação de diminutivo do português brasileiro. Revista de Estudos da Linguagem, v.8, n.1, 1999. Disponível em:

http://www.periodicos.letras.ufmg.br/index.php/relin/article/ view/2303. Acesso em: 29 jan. 2019.

LEITE, Y. F. Portuguese Stress and Related Rules. Tese de Doutorado. Universidade do Texas, 1974.

MACIEL, M. Gramática Descriptiva. 9 ed. Rio de Janeiro: Francisco Alves, 1925 [1916].

MARANTZ, A. Words and Things. Manuscrito. New York University, 2001. 
v. 9 (2)

154-172 maio-ago 2019
MENUZZI, S. On the prosody of the diminutive alternation -inho/zinho in Brazilian Portuguese. Manuscrito. Hil/University of Leiden, 1993.

SCHWINDT, L. C. O prefixo no português brasileiro: análise prosódica e lexical. DELTA, São Paulo, v. 17, n. 2, p. 175-207, 2001. Disponível em: <http://www.scielo.br/scielo.php?script=sci_arttext\&pid=S010244502001000200001\&lng=en\&nrm=iso >. Acesso em 29 Jan. 2019.

TAVARES, J.N.C. O uso dos sufixos -inho e -zinho no discurso dos pescadores artesanais. III Congresso Nacional de Linguística e Filologia, Rio de Janeiro, 1999. 